\title{
MODEL DIKLAT KEWIRAUSAHAAN BAGI REMAJA PUTUS SEKOLAH
}

\author{
Husaini Usman, Lantip Diat Prasaja, Sunarta \\ FT Universitas Negeri Yogyakarta (husain_usman@yahoo.com)
}

\begin{abstract}
Abstrak: Model Diklat Kewirausahaan bagi Remaja Putus Sekolah. Penelitian ini bertujuan untuk mendapatkan: (1) model diklat kewirausahaan bagi Remaja Putus Sekolah (RPS) di Propinsi DIY, (2) modul-modul diklat kewirausahaan berdasarkan hasil uji coba, dan (3) hasil pelaksanaan diklat kewirausahaan. Pendekatan kualitatif-interaktif dan penelitian\&pengembangan digunakan pada penelitian ini. RPS dipilih secara kuota dan purposif. Data dikumpulkan melalui wawancara mendalam dengan pejabat pemerintah dan 30 RPS. Data dianalisis dengan teknik deskriptif dan kualitatif. Hasil penelitian menemukan: (1) model pendidikan kewirausahaan meliputi sistem, struktur program diklat, komposisi antara teori dengan praktik, modul diklat, kriteria peserta, pelatih, metode, dan evaluasi diklat, (2) modul-modul ternyata layak digunakan untuk pendidikan kewirausahaan guna mengurangi kemiskinan dan pengangguran, dan (3) diklat kewirausaahaan terlaksana dengan sukses.
\end{abstract}

Kata Kunci: model pendidikan, kewirausahaan, kemiskinan, pengangguran

\begin{abstract}
A Model of the Entrepreneurship Training for Drop-out Teenagers. This study was aimed to reveal: (1) a model of an entrepreneurship training for drop-out teenagers in Yogyakarta province; (2) modules of the entrepreneurship training based on the results of the try-out; and (3) the results of the training implementation. The qualitative-interactive and research and development approach was used in this study. Thirty drop-out teenagers and government excutiveswere selected purposively for in-depth interviews. The data were analyzed using the descriptive and qualitative technique. The findings indicated that: (1) a model of an entrepreneurship training included the system, program structure, integration between theories and practices, modules, participant criteria, trainers, methods, and evaluation; (2) the modules were appropriate to be used in the training; and (3) the training was implemented successfully.
\end{abstract}

Keywords: training model, entrepreneurship

\section{PENDAHULUAN}

Masalah kemiskinan dan pengangguran di Indonesia merupakan masalah yang belum terselesaikan hingga saat ini. Menurut Biro Pusat Statistik, jumlah penduduk Indonesia pada tahun 2010 adalah 230 juta. Jumlah penduduk miskin di perkotaan $11,7 \%$ dan di pedesaan 17,8\% (Carunia Mulya Firdaus, 2010:6). Orang miskin menú- 
rut BPS adalah orang yang berpenghasilan Rp190.000/orang/bulan di pedesaan, sedangkan di perkotaan Rp230.000/ orang bulan atau orang yang berpenghasilan Rp6.333.33/orang/hari di pedesaan dan Rp7.666,66/orang/hari di perkotaan (Rachbini, 2010:7). Jumlah penduduk miskin di Indonesia menurut versi pemerintah adalah 30 juta, sedangkan menurut Bank Dunia 100 juta. Menurut Tokoh Agama (10 Januari 2011) 70 juta penerima bantuan beras untuk orang miskin (raskin) dan 76,4 juta penerima jaminan kesehatan masyarakat (jamkesmas). Kemiskinan antara lain disebabkan pengangguran. Pengangguran menurut Departemen Tenaga Kerja adalah seseorang yang bekerja di bawah 40 jam/minggu. Jumlah pengangguran tersebut sebagian besar masih berpendidikan SMP, SD, dan tidak pernah sekolah 4,92 juta, verpendidikan SMA 3,3 juta, dan sarjana 12 juta (CEO Garuda Group, 2010:12). Penduduk Propinsi DIY pada tahun 2010 ini berjumlah 3.439 .000 jiwa. Jumlah penduduk miskin di daerah pedesaan 274.310.000 jiwa dan di kota 311.470.000 jiwa (Berita Resmi BPS Nomor 43 Tahun 2009). Salah satu masalah di Provinsi DIY adalah banyaknya Remaja Putus Sekolah (RPS) yang masih miskin dan menganggur.

Upaya untuk mengatasi masalah kemiskinan dan pengangguran adalah berwirausaha. Untuk menghasilkan wirausaha yang sukses diperlukan diklat kewirausahaan. Oleh sebab itu, perlu diadakan penelitian tentang model diklat kewirausahaan bagi RPS dalam upaya mengurangi kemiskinan dan pengangguran. Di samping ber- wirausaha, usaha lain untuk mengatasi kemiskinan dan pengangguran adalah menciptakan lapangan kerja, mewujudkan ekonomi yang kuat, menciptakan keunggulan komparatif jangka panjang, kelembagaan dan pemerintahan yang kuat dan efektif, program bagi kaum miskin dan menganggur yang dirancang secara profesional, mengurangi budaya konsumtif, menghilangkan dualisme kota dan desa, merubah pola pikir perempuan adalah tenaga produktif dalam keluarga, dan membangun budaya keras sebagai mata pencaharian (Carunia Mulya Firdaus, 2010:6).

Diklat kewirausahaan tidak serta merta menghasilkan wirausaha yang sukses karena mereka tidak dapat dididik dan dilatih (Schramm (2010:18). Diklat kewirausahaan hanya berhasil jika melatih orang-orang yang mempunyai kharisma dalam dirinya. Kharisma ini hanya dimiliki oleh orangorang yang ingin mengubah dirinya dari bekerja pada orang lain menjadi bekerja sendiri, memiliki kepribadian senangdengan tantangan, berani mengambil risiko, inovatif, kreatif, dan gigih mewujudkan impiannya. "Bahkan di tangan seorang enterpreneur, kotoran dan barang rongsokan dapat diubah menjadi emas" (Andreas Harefa \& Eben Ezer Siadari, 2006:16).

Model diklat kewirausahaan saat ini umumnya dilaksanakan secara konvensional. Artinya, diklat dilaksanakan tanpa analisis kebutuhan, setelah diklat tidak ada evaluasinya, apalagi tindaklanjutnya. Diklat sering direncanakan hanya untuk kepentingan proyek dan dilaksanakan untukmenyukseskan pen- 
capaian target proyek. Setelah diklat, alumni diklat belum tentu mampu menciptakan lapangan kerja apalagi mengurangi kemiskinan dan pengangguran. Idealnya, setelah diklat kewirausahaan, alumninya mampu menciptakan lapangan kerja sehingga mampu mengurangi kemiskinan dan pengangguran baik bagi dirinya maupun anak buahnya. Permasalahannya adalah, "Bagaimana model diklat kewirausahaan bagi RPS? Apakah modul-modul diklat kewirausahaan berdasarkan analisis kebutuhan layak untuk dilatihkan? Bagaimana pelaksanaan diklat kewirausahaan?"

Model adalah contoh atau acuan atau ragam dari sesuatu yang akan dibuat. Model dibatasi pada analisis kebutuhan, sistem, struktur program, komposisi, modul, peserta, pelatih, metode, dan evaluasi. Noe (2008) memberikan model diklat dengan langkahlangkah yang disingkat ADDI (Analysis, Design, Development, and Implementation). KEWIRAUSAHAAN adalah singkatan dari: Kreatif, Enerjik, Wawasan luas, Inovatif, Risiko bisnis, Agresif, Ulet, Supel, Agresif, Hemat, Asa, Antusias, Negosiatif (Anonim, 2005:1). Kewirausahaan adalah kemampuan menghasilkan barang jasa secara: inovatif, kreatif, motivasi kuat, kerja keras, melihat dan memanfaatkan peluang, berani mengambil risiko, dan pantang menyerah untuk mewujudkan impian sehingga mendapatkan nilai tambah dan laku di pasaran (Andreas Harefa \& Eben Ezer Siadari, 2006:12-18; Schramm, 2010:18; dan Simanjuntak, 2010:18).

RPS adalah lulusan SD dan yang sederajat, SMP dan yang sederajat, SMA/SMK dan yang sederajat berusia kerja (18 tahun ke atas), berusia produktif (40 tahun ke bawah), penerima raskin dan jamkesmas, dan berpanghasilan kurang dari Rp6.350/orang/ hari. Tujuan penelitian Tahap I Tahun 2010 adalah untuk mendapatkan: (1) model diklat kewirausahaan bagi RPS di Propinsi DIY; (2) hasil uji coba kelayakan modul-modul diklat kewirausahaan bagi RPS berdasarkan analisis kebutuhan pelatihan.

\section{METODE}

Lokasi penelitian adalah Kabupaten Sleman, Kabupaten Bantul, Kabupaten Kulon Progo, Kabupaten Gunungkidul, dan Kota Yogyakarta. Penelitian ini menggunakan pendekatan penelitian dan pengembangan. RPS dipilih secara kuota dan purposif. Kuota artinya setiap kabupaten/kota ditetapkan enam RPS karena alasan dana, waktu, dan tenaga. Purpusif artinya RPS dipilih sesuai dengan tujuan penelitian, yaitu model pelatihan untuk RPS yang masih miskin dan menganggur dengan kriteria di atas. Data dikumpulkan melalui wawancara mendalam dengan pejabat pemerintah (Kepala Dinas Tenaga Kerja, Kepala Bappeda, pengelola Pusat Kegiatan Belajar Masyarakat Kabupaten/Kota di lingkungan Provinsi DIY) dan 30 RPS.

Peneliti melakukan audiensi dan wawancara mendalam dengan Kepala Dinas Tenaga Kerja dan Kepala Bappeda setempat. Audiensi bertujuan untuk menjelaskan tujuan dan manfaat penelitian. Wawancara bertujuan untuk mendapatkan informasi tentang kebu- 
tuhan diklat kewirausahaan yang dibutuhkan kabupaten/kota dan calon RPS yang akan mengikuti diklat. Setelah audiensi diadakan wawancara mendalam dengan Kepala Dinas Tenaga Kerja dan Kepala Bappeda masing-masing. Hasil wawancara langsung dikumpulkan dan dianalisis dengan teknik persentase dan rata-rata (statistik deskriptif). Selanjutnya, untuk mendapatkan kebutuhan diklat kewirausahaan bagi RPS, peneliti mewawancarai 6 RPS. Pengumpulan informasi dilakukan dengan mewawancarai RPS satu demi satu untuk menetapkan diklat yang sangat dibutuhkan RPS sebagai bekal berwirausaha. Hasil wawancara dikumpulkan dan dianalisis teknik deskriptif (persentase dan ratarata) serta analisis data kualitatif model Creswell (2008:244).

Pengembangan model diklat kewirausahaan diperoleh dengan menggunakan metode Penelitian dan Pengembangan (Research and Development -R\&D). Alasan memilih metode R\&D adalah karena metode ini: (1) digunakan untuk menghasilkan model tertentu; (2) cocok untuk pengembangan bidang-bidang yang terkait dengan teknologi diklat; (3) untuk mengembangkan model. Prosedur R\&D memodifikasi model Borg \& Gall (2007:775) yang meliputi delapan tahap yaitu: (1) mengumpulkan informasi; (2) merencanakan; (3) mengembangkan pra-rencana model; (4) melakukan uji pendahuluan secara terbatas (in pertama); (5) melakukan revisi modul; (6) melakukan uji modul di lapangan (on); (7) merevisi modul akhir; dan (8) menyebarkanluaskan pedoman diklat (in ke- dua) dan melaksanakan model. Langkah 1 sampai 3 adalah langkah untuk menemukan model diklat. Data model diklat analisis secara kualitatif dengan model Creswell (2008:244).

Desain penelitian kualitatif bersifat sementara (emergent) yaitu dapat diubah-ubah sesuai realitas sosial di lapangan. Pemilihan informan bersifat bola salju (snow-ball) yaitu informan bertambah terus sampai informasi yang didapat jenuh (redundancy). Informan utama adalah pelaksana diklat di Pusat Kegiatan Belajar Masyarakat (PKBM). Instrumen penelitian adalah peneliti sendiri (human instrument). Pengumpulan data menggunakan pendekatan inkuiri naturalistik. Upaya peningkatan kredibilitas hasil penelitian dicapai melalui: (1) kegiatan; (2) diskusi dengan teman sejawat; (3) analisis kasus negatif; (4) referensi yang cukup; (5) pengecekan oleh subjek penelitian (member check).

\section{HASIL}

\section{Pengembangan Model Diklat Kewira- usahaan}

Langkah ke-1 dari model R\&D adalah mengadakan penelitian melalui pengumpulan informasi. Informasi yang dimaksud adalah informasi kebutuhan diklat baik yang dibutuhkan kabupatan/kota di lingkungan Propinsi DIY maupun yang dibutuhkan RPS calon peserta diklat. Langkah ke-2 dari model R\&D selanjutnya adalah merencanakan pra-rencana model diklat kewirausahaan. Berdasarkan hasil wawancara mendalam dengan pelaksana diklat di kabupaten/kota masing- 
masing, maka ditemukan pra-rencana model diklat kewirausahaan dengan sistem in-on-in seperti tampak pada Gambar 1 berikut.

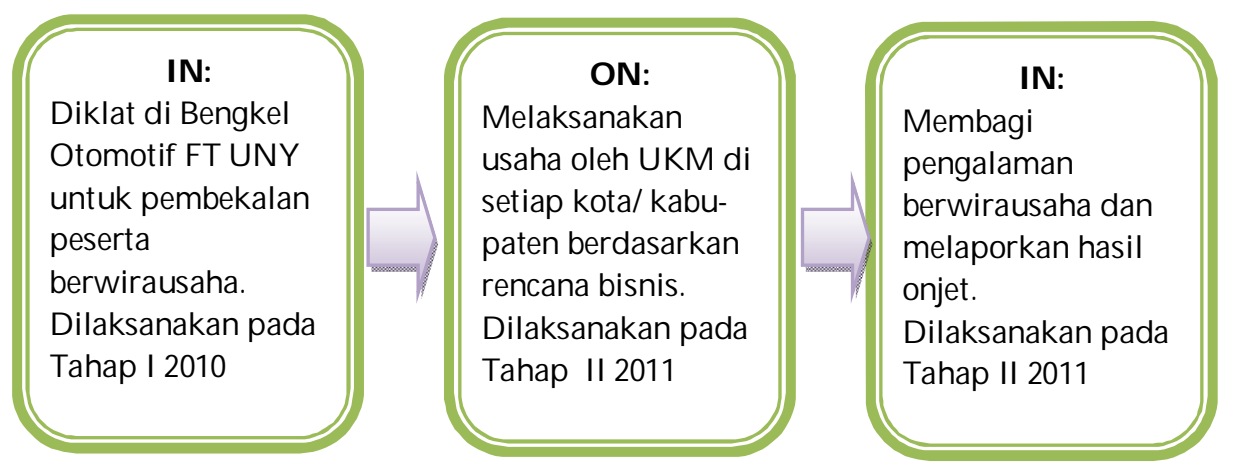

\section{Gambar 1: Prarencana Model Diklat Kewirausahaan}

Langkah ke-3 dari pendekatan R\&D adalah mengembangkan prarencana model menjadi model. Berdasarkan hasil wawancara dan analisis kebutuhan diklat, didapat struktur program diklat kewirausahaan seperti Tabel 1 berikut. Struktur ini dikembangkan pada Gambar 1.

Tabel 1. Struktur Program Diklat Kewirausahaan

\begin{tabular}{lclcl}
\hline \multicolumn{1}{c}{ Unsur } & No & \multicolumn{1}{c}{ Materi Pelatihan (Modul) } & Jumlah Jam & Keteterangan \\
\hline Penunjang & 1 & Manajemen Perubahan & 2 & Teori \\
Pokok & 2 & Manajemen Bengkel & 4 & Teori \\
& 3 & Mesin dan Pemindahan Tenaga & 10 & Praktik \\
& 4 & Sistem Kelistrikan Sepeda Motor & 10 & Praktik \\
& 5 & Kewirausahaan & 2 & Teori \\
& 6 & Manajemen Bisnis & 2 & Praktik \\
& & Jumlah & 30 & \\
\hline
\end{tabular}

Berdasarkan hasil wawancara dan diskusi, didapat model diklat kewirausahaan seperti terlihat pada Gambar 2.

\section{Uji Coba Modul dan Evaluasi Dik- lat Kewirausahaan}

Tahap ke-4 dari R\&D adalah melakukan uji pendahuluan di lapangan. Enam modul yang ditulis oleh penulis adalah seperti Tabel 1 dan diujicobakan melalui pelaksanaan diklat kewira- usahaan pada inset 1 . Keenam modul diklat dibagikan kepada semua peserta diklat sebelum setiap sesi diklat dimulai untuk diujicobakan. Pada akhir setiap sesi mata diklat, semua peserta diminta mengisi lembaran evaluasi modul diklat. Berdasarkan evaluasi terhadap peserta berupa pre-test dan posttest ternyata hasilnya menunjukkan peningkatan yang menggembirakan. 


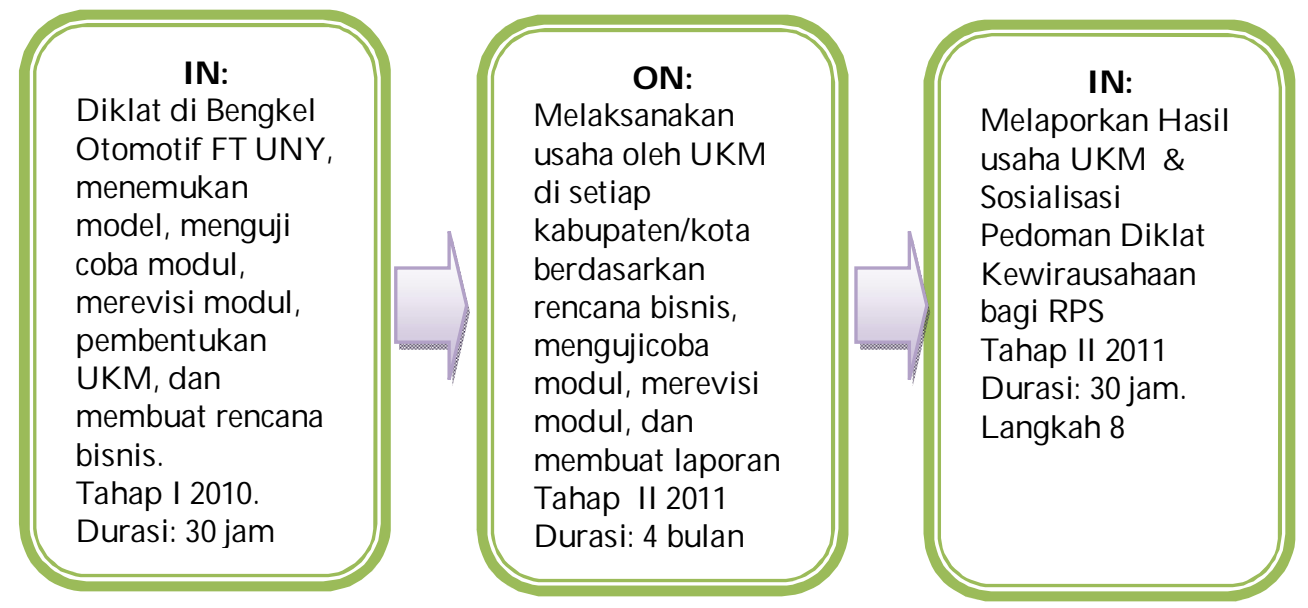

\section{Gambar 2: Model Diklat Kewirausahaan bagi RPS}

Pelatih membuka diklat dengan pohon harapan dan membangun komitmen belajar. Pelatih juga memberikan selingan-selingan berupa ice breaking pada saat yang tepat dengan konteks materi yang tepat pula sehingga tidak ada yang mengantuk dan suasana diklat aktif dan menyenangkan. Setiap akhir diklat, pada malam harinya di penginapan diadakan refleksi dan diskusi. Hasil refleksi umumnya psoitif sehingga diklat serupa layak dijadikan model. Pada saat akhir pelaksanaan diklat servis sepeda motor, peserta diminta membentuk Usaha Kecil Menengah (UKM). Kelima UKM ditugaskan membuat rencana bisnis untuk dilaksanakan pada tahap on tahun 2011.

\section{Pengembangan Model Diklat Kewira- usahaan}

Dari Tabel 1 di atas dapat diketahui bahwa dari 10 intervee ternyata 8 intervee $(80 \%)$ memprioritaskan diklat servis sepeda motor. Alasannya karena: (1)bepergian dengan sepeda motor lebih hemat biayanya disbandingkan dengan naik kendaraan umum; (2) dapat langsung mencapai tujuan ke pelosok-pelosok tanpa harus berganti kendaraan lain atau harus berjalan kaki; (3) fasilitas kendaraan umum berdesak-desakan; (4) kendaraan umum belum tentu aman (sopir suka mengabaikan peraturan lalu lintas); (5) kendaraan umum tidak nyaman (panas); (6) kendaraan umum tidak sehat (sopir dan penumpang lain merokok); (7) kendaraan umum suka menunggu penumpang sampai penuh atau menyetopi penumpang sehingga boros waktu; (8) jumlah kendaraan umum terbatas; (9) petugas kendaraan umum tidak ramah; (10) jalan semakin macet; (11) kemudahan memiliki sepeda motor melalui kredit; (12) isu subsidi BBM untuk kendaraan roda empat akan dicabut; (13) semakin banyaknya warga DIY yang membeli sepeda mo- 
tor; (14) sepeda motor yang akan diservis bukan hanya berasal dari Provinsi DIY saja tetapi juga dari propinsi lainnya; (15) sepeda motor ada masa pakainya sehingga harus diservis secara berkala; (16) tiap keluarga baik kaya maupun miskin sudah memiliki sepeda motor; (17) dengan modal Rp 200.000 sudah dapat membawa pulang motor kredit; (18) biaya perjalanan dengan sepeda motor lebih irit; (19) dengan dimiliknya keterampilan servis sepeda motor minimal mampu menservis motor sendiri dan membuka usaha bengkel sepeda motor.

Beberapa kelebihan alasan yang dikemukakan di atas mendukung temuan penelitian Ndy, dkk (2011:25) yang menyatakan bahwa tahun 2010 jumlah sepeda motor di Jabodetabek bertambah 1,5 juta unit. Penambahan jumlah sepeda motor ini terjadi pula di Propinsi DIY. Pilihan warga Jabodetabek menggunakan sepeda motor karena kondisi angkutan umum sangat buruk. Kondisi angkutan umum di Jabodetabek tidak jauh berbeda dengan kondisi angkutan umum di Propinsi DIY. Temuan Ndy, dkk (2011: 25) adalah banyak penumpang angkutan umum pindah ke sepeda motor karena lebih mudah, murah, praktis, dan cepat sampai tujuan. Temuan ini tidak berbeda dengan persepsi penumpang angkutan umum Propinsi DIY.

Penelitian Caesar Alexey, dkk. (2011:35), banyaknya pengguna angkutan umum beralih ke sepeda motor dipicu oleh kemudahan mendapatkan kredit sepeda motor. Sepeda motor seharga Rp12,5 juta hanya dengan uang muka Rp400 ribu dengan cicilan bervariatif tergantung lamanya angsuran. Temuan ini tidak jauh berbeda dengan kemudahan mengangsur sepeda motor yang terjadi di Propinsi DIY. Namun, menurut Caesar Alexey dkk. (2011:25), “ada risiko kecelakaan fatal di balik biaya transportasi murah, kecepatan, kepraktisan, serta kemudahan memiliki sepeda motor. Jumlah sepeda motor yang terlalu banyak dan perilaku berlalu lintas yang buruk membuat risiko kecelakaan." Salah satu strategi untuk menanggulangi berbagai dampak yang muncul dibutuhkan pemeliharaan berkala terhadap alat transportasi tersebut. Permasalahannya ádalah jumlah bengkel sepeda motor belum seimbang dengan pertumbuhan kendaraan roda dua. Untuk menjawab permasalahan tersebut perlu dilaksanakan diklat bagi RPS yang aplikatif agar memiliki keterampilan dalam berwirausaha dengan menggunakan suatu model yang sesuai bagi masyarakat. Adapun model yang dikembangkan dalam penelitian ini adalah in-on-in.

In yang pertama adalah diklat tahap pertama, disebut sebagai in-service education and training (inset 1) bertempat di bengkel servis sepeda motor FT UNY. Pada akhir inset 1, peserta diberi tugas membetuk Usaha Kecil Mandiri (UKM) berdasarkan kabupaten/kota yang terdiri atas 6 RPS. Kelompok ditugaskan membuat rencana bisnis berupa proposal usaha servis sepeda motor. Rencana bisnis ini akan diimplementasikan pada onjet.

On adalah diklat di tempat usaha servis sepeda motor di kabupaten/kota masing-masing disebut on the job 
education and training atau onjet. Pada onjet, UKM mempraktikkan rencana bisnis yang telah dibuat pada akhir inset 1 . Onjet akan dilaksanakan pada tahap 2 tahun 2011. Inset 2 adalah diklat yang dilaksanakan setelah onjet. Pada inset 2, masing-masing kelompok diminta berbagi pengalaman onjet dan melaporkan hasil onjet melalui presentasi dan diskusi serta membuat pedoman pelaksanaan diklat kewirausahaan dan tim peneliti menyosialisasikan model tersebut. Inset 2 akan dilaksanakan pada tahap 2 tahun 2011.

Berdasarkan inset 1 di atas, tampak bahwa komposisi alokasi waktu untuk teori (diskusi) dengan praktik adalah 8:22 atau 27\%:73\%. Tujuannnya adalah agar alumni diklat lebih banyak berpraktik daripada berteori sehingga mereka terampil dalam menservis sepeda motor. Modul diklat ditulis oleh penulis yang kompeten dan berpengalaman. Hasilnya diucujicobakan pada inset 1 untuk mendapat masukan dari peserta diklat. Inset dilaksanakan dengan durasi waktu 30 jam diklat @ 45 menit. Injet merupakan penerapan langkah 1 sampai 5 dari R\&D. Pelaksanaan injet 1 berdasarkan rambu-rambu yang telah dibuat tim peneliti.

Berdasarkan Gambar 2 terdapat perubahan pra-model menjadi model. Pada inset 1 ada tambahan membuat struktur program, menulis 6 modul, ujicoba modul, revisi modul, pembentukan UKM, dan membuat rencana bisnis. Onjet (Penelitian Tahap 2 Tahun 2011) adalah diklat dalam bentuk mempraktikkan berwirausaha dengan stimulus modal bergilir penelitian. Setiap kelompok membuka dan melak- sanakan usaha servis sepeda motor sesuai dengan rencana bisnis yang telah dibuat pada injet 1 , mengujicoba semua modul yang telah direvisi pada injet 1, membuat laporan hasil usaha, mencatat kendala-kendala dan pendorongnya dalam usaha, mencatat kelemahan modul injet 1 yang perlu direvisi. Onjet dilaksanakan selama empat bulan setelah mendapat bantuan modal bergulir dari dana penelitian ini. Onjet merupakan penerapan langkah 6 dan 7 dari R \& D. Pelaksanaan onjet berdasarkan rambu-rambu yang telah dibuat tim peneliti. Pelaksanaan onjet berdasarkan rambu-rambu yang telah dibuat tim peneliti.

Pada inset 2 (Penelitian Tahap 2 Tahun 2011), diklat diisi dengan kegiatan presentasi dan diskusi laporan pelaksanaan onjet dan hasilnya. Tujuannya adalah untuk berbagi pengalaman berwirausaha di onjet masing-masing. Inset 2 diselenggarakan di UNY dalam durasi 30 jam pelatihan Inset 2 merupakan penerapan langkah 8 dari R\&D. Selanjutnya, temuan model diklat kewirausahaan dengan sistem inon-in bagi RPS dibandingkan dengan model diklat yang selama ini dilaksanakan di PKBM kabupaten/kota di Propinsi DIY dan model diklat Noe (2005). Model diklat kewirausahaan dengan sistem in-on-in bagi RPS ternyata memiliki persamaan, yaitu diklat meliputi: analisis kebutuhan diklat, perencanaan diklat, pelaksanaan diklat, dan pengevaluasian diklat. Perbedaan model diklat kewirausahaan dengan sistem in-on-in bagi RPS dengan model diklat yang dilakukan di PKBM kabupaten/kota di Propinsi DIY 
dan model diklat Noe (2005) sekaligus kelebihannya adalah: (1) sistem in-on-in memberi kesempatan kepada peserta untuk menerapkan materi yang diterimanya di injet 1 pada onjet; (2) in-on-in memberi kesempatan kepada penulis diklat untuk merevisi modul diklat berdasarkan masukan peserta diklat untukdigunakan pada diklat berikutnya sehingga materi selalu up to date; (3) sistem in-on-in memberikan kesempatan kepada semua peserta untuk berbagi pengalaman selama onjet; dan (4) sistem in-on-in memberi kesempatan kepada penulis modul untuk merevisi kembali bedasarkan masukan peserta pada onjet. Kelemahan sistem in-on-in dibandingkan dengan model diklat yang dilakukan di PKBM kabupaten/kota di Propinsi DIY dan model diklat Noe (2005) adalah sistem in-on-in memerlukan tenaga, biaya, dan waktu yang banyak karena peserta dilatih dua kali (inset 1 dan 2), sedangkan model diklat yang dilakukan di PKBM kabupaten/kota di Propinsi DIY dan model diklat Noe (2005) cukup satu kali diklat. Kelemahan lainnya adalah revisi modul, pemantauan onjet, pembuatan laporan hasil onjet semuanya memerlukan tenaga, waktu, dan biaya. Pelaksanaan injet 2 berdasarkan rambu-rambu yang telah dibuat tim peneliti.

\section{Hasil Uji Coba Modul Diklat Ke- wirausahaan}

Modul manajemen perubahan perlu dilatihkan agar RPS mau dan mampu mengubah pola pikir, pola rasa, dan pola sikap untuk berwirausaha. Manajemen perubahan diharapkan mampu membentuk adanya perubahan dari diri sendiri untuk bekerja sendiri bukan bekerja kepada orang lain (Schramm, 2010:18). Diklat kewirausahaan tidak ada gunanya jika peserta diklat tidak mau mengubah dirinya sendiri dari bekerja dengan orang lain menjadi bekerja sendiri (Schramm, 2010:18).

Manajemen bengkel, mesin dan pemindahan tenaga, sistem kelistrikan sepeda motor perlu dilatihkan agar RPS mampu membuka usaha servis sepeda motor. Kewirausahaan perlu dilatihkan agar RPS memahami ciri-ciri wirausaha yang sukses dan mengetahui serta menerapkan cara menjadi wirausaha yang sukses. Manajemen bisnis perlu dilatihkan agar RPS mempunyai rencana bisnis yang jelas. Schramm (2010) menyatakan bahwa jika pengusaha memiliki rencana bisnis yang jelas, dipastikan usahanya pun akan berhasil.

Modul ditulis oleh penulis yang kompeten dan berpengalaman. Sistematika p en ulis a n m od ul dibuat sesederhana mungkin agar mudah dipahami RPS. Sistematika modul yang disusun berisi: A. Tujuan Materi. B. Materi. C. Metode. D. Evaluasi. E. Lampiran (pre-test, tugas individual, tugas kelompok, penyajian hasil diskusi, penguatan fasilitator, dan post-test). Pemilihan kata disesuaikan dengan tingkat pendidikan RPS agar mudah dipahami. Isi materi dipilih yang paling mendasar dan bermanfaat untuk berwirausaha. Ilustrasi berupa contoh dan gambargambar dibuat contoh nyata dan gambar yang jelas, jika mungkin gambarnya tiga dimensi (M. Jamaluddin, 2009). Jumlah lembar juga dibatasi se- 
minimal mungkin karena waktunya yang relatif singkat. Di samping itu, untuk menghindarkan rasa takut di kalangan peserta jika modulnya tampak tebal. Terlebih-lebih RPS biasanya sudah enggan membaca yang memerlukan waktu relatif lama. Hasilnya didiskusikan dengan teman sejawat yang kompeten untuk mendapatkan expert judment, kemudian diujicobakan secara terbatas terhadap 30 RPS yang mengikuti diklat servis sepeda motor.

\section{Pelaksanaan Diklat Kewirausahaan}

Kenyataan yang sering terjadi pada diklat-diklat adalah evaluasi pelatih oleh peserta hanyalah untuk kepentingan formalitas saja karena walaupun ada pelatih yang dinilai sangat jelek tetapi tetap saja mendapat tugas melatih. Hasil evaluasi seharusnya ditindaklanjuti dengan pembinaan. Dalam model ini, jika ada pelatih yang mendapat nilai sangat jelek dan cukup, maka pelatih yang bersangkutan dibina dulu sampai menjadi pelatih yang layak, barulah boleh melatih lagi. Dalam model ini pelatih yang boleh melatih hanyalah yang bernilai baik saja atau jika mungkin telah memperoleh sertifikat pelatih oleh lembaga yang berwenang. Hasil refleksi oleh peserta cenderung positif karena fasilitas yang diberikan oleh pelatih dan penyelenggara relatif baik.

Usaha Kecil Mandiri perlu dibentuk karena menurut Simanjuntak (2010), "Di era globalisasi ini, perusahaan-perusahaan besar terbukti selalu mengalami kesulitan menghadapi persaingan yang kian tajam. Sebaliknya, kelom- pok usaha kecil mampu menghadapinya karena lebih lincah, fleksibel, dan cepat mengambil keputusan." Sebagai contoh, ketika negara kita mengalami krisis ekonomi pada tahun 1998 ternyata perusahaan besar banyak yang gulung tikar, sementara perusahaan kecil masih tetap bertahan. Ekspor Amerika Serikat dan Jerman 50\% merupakan produk perusahaan kecil dengan karyawan kurang dari 20 orang (Simanjuntak, 2010:18). Selanjutnya, ditambahkan Simanjuntak (2010), "Tantangan bagi Indonesia adalah menyiapkan tenaga berkemampuan mandiri yang merupakan bagian dari kelompok usaha kecil tersebut." Setiap UKM wajib membuat rencana bisnis karena jika pengusaha memiliki rencana bisnis yang jelas, dipastikan usahanya pun akan berhasil (Schramm, 2010:18).

\section{PENUTUP}

\section{Kesimpulan}

- Pelaksanaan in-service education and training (inset 1) cukup berhasil sehingga layak dilanjutkan pada tahap on the job education and training (onjet) dan in-service education and training (inset 2).

- Modul yang disusun dan telah diujicobakan sangat layak untuk diaplikasikan pada model in-on-in bagi Remaja Putus Sekolah dalam upaya mengurangi jumlah pengangguran dan kemiskinan.

- Model diklat kewirausahaan yang cocok bagi Remaja Putus Sekolah adalah model in-on-in. 


\section{Saran}

- Agar dalam pelaksanaan model inservice education and training (inset 2) bisa berjalan lebih optimal, maka perlu dukungan dan komitmen dari berbagai pihak.

- Agar modul dan model in-on-in yang telah diujicobakan kepada Remaja Putus Sekolah bisa dilanjutkan pada tahun-tahun mendatang dalam usaha mengurangi jumlah pengangguran dan kemiskinan di propinsi DIY.

\section{UCAPAN TERIMA KASIH}

Tim peneliti mengucapkan terima kasih kepada Dewan Redaksi Cakrawala Pendidikan, Prof. Dr. Burhan Nurgiantoro dan staf yang telah memfasilitasi terbitnya artikel ini untuk dimuat di Cakrawala Pendidikan (Akreditasi B). Terima kasih kepada Direktorat Jenderal Pendidikan Tinggi Kementerian Pendidikan Nasional yang telah membiayai penelitian Strategis Nasional ini.

\section{DAFTAR PUSTAKA}

Anreas Harefa \& Eben Ezer Siadari. 2006. The Ciputra Way Praktik Terbaik Menjadi Entrepreneur Sejati. Jakarta: PT. Alex Media Komputindo Kelompok Gramedia.

Borg, W.R., \& Gall, M.D. 2007. Educational Research: An Introduction. New York: Longman.

Berita Resmi BPS Nomor 43 Tahun 2009 tentang Data Penduduk.

Biro Pusat Statistik. 2009. Statistik Indonesia, Jakarta: BPS.
Caesa Alaxey, Neli Triana, Agnes Rita, Andy Reza, Cokorda Yudistira, Ratih Prahesti, dan Pransisca Romana Nini. 2011. Sehari 21 Pengendara Terlibat Kecelakaan, Kompas, 31 Januari, halaman 25.

Carunia Mulya Firdaus. 2010. Empat Syarat Ellwood Tidak Cukup. Kompas, 18 September, halaman 6.

CEO Garuda Group. 2010. Pendidikan Kewirausahaan Harus Campur Tangan Pemerintah, Kompas, 20 September, halaman 12.

Creswell, J.W. 2008. Educational Research Planning, Conducting, and Evaluating Quantitative and Qualitative Research. Third Edition. Upper Sadle River, New Jersey: Perason Education.

Direkrorat Tenaga Kependidikan. 2010. Kewirausahaan. Bahan Pelatihan Penguatan Kepala Sekolah. Jakarta: Direktorat Jenderal Peningkatan Mutu Pendidik dan Tenaga Kependidikan.

Harvey, D., \& Bowin, R.B. 2006. Human Resources Management An Expriental Approach. London: Prentice-Hall International, Inc.

Keputusan Ketua Lembaga Administrasi Negara Nomor 541/XIII/ 10/6/2001 tentang Evaluasi Pelaksanan Diklat PNS.

Moerdiyanto, 2009. Pengembangan Model Pendidikan Kewirausahaan Bagi Remaja Putus Sekolah 
Korban Gempa Sebagai Usaha Pengentasan Kemiskinan di Kabupaten Bantul DIY. Prosiding Deseminasi Hasil-hasil Penelitian Tingkat Nasional, ISBN 978602-8429-27-6 halaman 150.

Ndy, Nel, Pro, Art, Ec, Cok, Rts, Trd. 2011. Sepeda Motor Alternatif Kendaraan yang Mudah didapat, Murah, Cepat, Praktis, tetapi Mematikan, Kompas, 31 Januari, halaman 25.

Noe, R.A. 2008. Employee Training and Development. Third Edition. New York: McGraw-Hill.
Rachbini, Didik, J. 2010. Demokrasi Minus Kesejahteraan. Kompas, 6 Agustus 2010, halaman 7.

Scramm, C.J. 2010. Wirausaha Tidak Bisa Dilatihkan, Kompas, 18 November, halaman 18.

Simanjuntak, P.J. 2010. Wirausaha Tidak Bisa Dilatihkan, Kompas, 18 November, halaman 18.

Suripno\&Heri Purwanto, 2008. Faktorfaktor yang Mempengaruhi Tingkat Kemiskinan di Indonesia. Economia, ISSN 1858-2648, Vol.2, No.2, Hal.46. 